\title{
Extração de substratos para obtenção da concentração de micronutrien- tes disponíveis para a rúcula
}

\author{
Mônica Ferreira de Abreu; Patrícia Heloá dos Santos; Pedro Roberto Furlani; Cleide Aparecida de Abreu \\ ${ }^{1}$ Instituto Agronômico, Centro Pesquisa e Desenvolv. Solos e Recursos Ambientais; C. Postal 28, 13012-970 Campinas-SP; \\ monica@iac.sp.gov.br
}

\section{RESUMO}

Vários desequilíbrios fisiológicos freqüentemente ocorrem em plantas cultivadas em substratos sem solo, causados pela falta ou excesso de micronutrientes, até o momento, não existe um método de rotina adequado para avaliar a disponibilidade deles para as plantas. Portanto, neste trabalho avaliou-se a eficiência dos métodos que utilizam extratos em água (1:1,5 e o extrato de saturação), e o extrato com solução de DTPA/CaCl ${ }_{2}$ para avaliar a concentração disponível de micronutrientes disponíveis para a Eruca sativa L. (rúcula) cultivada em substratos. O experimento foi conduzido em casa de vegetação, utilizando delineamento inteiramente ao acaso em esquema fatorial 3X4, com cinco repetições. Os tratamentos constituíram-se de tipos de substratos (casca de pinus, fibra de coco e turfa) e quatro concentrações de micronutrientes. Os substratos foram saturados e incubados com as soluções nutritivas até estabilizar a condutividade elétrica. Após, o substrato de cada parcela foi dividido, sendo uma parte para determinar os níveis do $\mathrm{B}, \mathrm{Cu}, \mathrm{Fe}, \mathrm{Mn}$ e Zn pelos métodos 1:1,5, extrato de saturação e DTPA/ $\mathrm{CaCl}_{2}$; a outra parte foi utilizada para cultivo da rúcula por 45 dias. De maneira geral, os métodos testados foram ineficientes em avaliar a disponibilidade de $\mathrm{Cu}, \mathrm{Fe}$, Mn e Zn para a rúcula. Por outro lado, houve correlação positiva entre as concentrações de B nos extratos obtidos pelos diversos métodos e a concentração de $\mathrm{B}$ na parte aérea da rúcula, com $r>0,98^{* *}$, independentemente do substrato utilizado. Todos os métodos podem ser utilizados na determinação do teor disponível de B às plantas, destacando-se o extrato de saturação com os melhores resultados.

Palavras-chave: Eruca sativa, análise química, casca de pinus, fibra de coco, turfa, extrato aquoso, método DTPA/CaCl, extrato de saturação.

\begin{abstract}
Extracting procedures to assess micronutrients availability for arugula plants

Physiological unbalances caused by micronutrient excess or deficiency are frequent in plants grown in soilless substrates and there exist no adequate routine method of analysis to assess micronutrient availability in the substrates. Therefore, the efficacy of water extracts (1:1.5 and saturation extract) and DTPA/CaCl extract was evaluated to assess micronutrient availability to Eruca sativa L. (arugula) grown in soilless substrates. The experiment was carried out in a greenhouse at Campinas, São Paulo State, Brazil, in a completely randomized design, arranged in a $3 \times 4$ factorial, with five replications. The treatments consisted of three substrate types (pinus bark, coir and peat) and four micronutrient concentrations. Substrates were saturated and incubated with nutrient solutions until electrical conductivity became constant. After that, each treated substrate sample was subdivided: one part for chemical analysis and the other to grow arugula plants during 45 days. On the overall, the tested methods were all inefficient to assess $\mathrm{Cu}, \mathrm{Fe}, \mathrm{Mn}$ and $\mathrm{Zn}$ availability to arugula. On the other hand, there was a positive correlation between leaf $\mathrm{B}$ concentration and $\mathrm{B}$ concentration in the different extracts $\left(r>0.98^{* *}\right)$, independently of the substrate used. The best results were obtained with the saturation extract, but all methods can be used in routine analysis to assess B availability to plants of arugula.
\end{abstract}

Keywords: Eruca sativa, substrates, pinus bark, coconut fiber, peat, water extracts, DTPA/ $\mathrm{CaCl}_{2}$ method, saturation extract.

\section{(Recebido para publicação em 14 de setembro de 2006; aceito em 11 de setembro de 2007)}

$\mathrm{N}$ o Brasil, praticamente todo o setor de produção de mudas e de plantas envasadas, principalmente na floricultura, está usando substratos cuja produção mensal é da ordem de 30.000 t $\left(60.000 \mathrm{~m}^{3}\right)$, com tendência de crescimento (Bataglia \& Furlani, 2004).

A diversidade de substratos é grande, principalmente no que se refere à sua origem refletindo na variabilidade de suas características químicas e físicas, fazendo com que o manejo da adubação seja bastante complexo. Até recentemente, as pesquisas enfocando respostas à adubação foram concentradas nos macronutrientes. Com relação aos micronutrientes muito pouco foi feito, ape- sar de serem comuns os desequilíbrios nutricionais causados, principalmente por $\mathrm{Cu}$ e B. A toxicidade de $\mathrm{Cu}$ foi observada com o cultivo de petúnia, em substrato contendo turfa, onde a dose de $3 \mathrm{mg} \mathrm{L}^{-1}$ foi prejudicial ao desenvolvimento das plantas (Bucher \& Schenk, 2000). Boaventura (2003), estudando a demanda por nutrientes de mudas cítricas produzidas em substrato, verificou que aos 250 dias após o transplante, o porta-enxerto limão cravo que recebeu fertirrigação, havia acumulado 20\% mais Cu em relação ao que recebeu fertilizante de liberação lenta. Para o porta-enxerto citrumelo "Swingle" o acúmulo de Cu em fertirrigação foi 37\% superior quando comparado ao mesmo porta-enxerto sob fertilizante de liberação lenta. Quanto ao B, a sua toxicidade foi observada em porta-enxertos de citros (Mattos Júnior. et al., 1995) e associada a teores de boro maiores que 5 mg kg-1 no substrato (extraído com água quente). Esses autores observaram que a toxicidade de B causou menor crescimento do material vegetal, com conseqüente atraso no período de formação da muda e perda da qualidade. A deficiência de $\mathrm{B}$ em clones híbridos de Eucalipytus grandis com Eucalipytus urophylla crescidos em substrato do tipo Plantmax ocasionou folhas novas pequenas, deformadas, espessas, com 
Tabela 1. Concentrações dos micronutrientes, pH e CE na solução utilizada para saturação dos substratos (concentration of micronutrients, $\mathrm{pH}$ and $\mathrm{CE}$ on the utilized solution for saturation of the substrates). Campinas, IAC, 2005.

\begin{tabular}{|c|c|c|c|c|}
\hline & \multicolumn{4}{|c|}{ Solução Nutritiva ${ }^{1}$} \\
\hline & Solução 1 & Solução 5 & Solução 10 & Solução 20 \\
\hline \multirow[t]{2}{*}{$\mathrm{pH}$} & 4,52 & 4,52 & 4,51 & 4,50 \\
\hline & \multicolumn{4}{|c|}{ dS $\mathbf{m}^{-1}$} \\
\hline \multirow[t]{3}{*}{ CE } & 1,79 & 1,86 & 1,90 & 2,10 \\
\hline & \multicolumn{4}{|c|}{ Concentração de elementos na solução ${ }^{2}$} \\
\hline & \multicolumn{4}{|c|}{$\mathrm{mg} \mathrm{L}^{-1}$} \\
\hline B & 0,61 & 3,51 & 5,65 & 11,19 \\
\hline $\mathrm{Cu}$ & 0,13 & 0,72 & 1,16 & 2,34 \\
\hline $\mathrm{Fe}$ & 2,49 & 10,88 & 21,15 & 41,59 \\
\hline $\mathrm{Mn}$ & 0,64 & 3,29 & 5,20 & 9,98 \\
\hline $\mathrm{Zn}$ & 0,25 & 1,27 & 2,13 & 4,05 \\
\hline
\end{tabular}

1Solução nutritiva padrão baseada em Furlani et al., 1999: Solução 1=Concentração padrão; Solução 5, 10 e 20 = 5, 10 e 20 vezes a concentração de micronutrientes da solução padrão. Os macronutrientes foram mantidos constantes em todas as soluções; ${ }^{2}$ Concentração determinada por ICP-OES ( ${ }^{1}$ standard solution based on Furlani et al., 1999: Solution 1 = standard concentration; Solution 5, 10 and $20=5,10$ and 20 times the concentration of micronutrients of the standard solution. The macronutrients were maintained constant in all solutions; ${ }^{2}$ Concentration determined through ICP-OES)

clorose marginal e presença de nervuras salientes nas folhas medianas intermediárias (Silveira et al., 2002).

Portanto, a recomendação de adubação com micronutrientes não pode ser indiscriminada, o que afeta a qualidade da colheita e o custo de produção. Para se evitar perdas na produção pela falta ou excesso da aplicação de nutrientes para uma determinada cultura, a avaliação dos teores de micronutrientes disponíveis é fundamental, necessitandose de métodos que apresentem boas correlações com teores obtidos nas plantas (Abreu et al., 2002).

Existem vários métodos de extração que atualmente estão sendo utilizados rotineiramente em alguns países. Nos Estados Unidos, existe certa preferência pelo extrato de saturação, enquanto na Holanda, tem-se adotado a extração com água em baixas diluições $(1: 1,5)$ (Sonneveld et al., 1974; Sonneveld, 1988). O Comitê Europeu de Normatização (CEN) recomenda a extração com água na relação 1:5 para determinação de macronutrientes (CEN, 2003b) e o quelante DTPA/CaCl $1+5$ (v/ v) método (CAT) para determinação dos micronutrientes (CEN, 2003a).

No Brasil, para os micronutrientes, não há consenso sobre qual o método mais adequado a ser usado. Abreu et al. (2004), estudando a capacidade discriminativa dos diferentes extratores aquosos em determinar os micronutrientes aplicados via adubação, concluíram que foi possível avaliar os teores de Fe, Mn e Zn quando estes estavam presentes em altas concentrações, e para o $\mathrm{Cu}$ nenhum extrator aquoso foi considerado promissor. Contudo, este trabalho foi preliminar e não levou em consideração a absorção de micronutrientes pelas plantas, somente a capacidade extrativa de cada método, o que o impede de ser conclusivo.

Considerando que os substratos são muito heterogêneos na sua composição e que esta influencia a disponibilidade de micronutrientes, é importante selecionar um método que seja eficiente em avaliar a disponibilidade de micronutrientes. Assim, as recomendações de adubações para as diferentes plantas cultivadas em substratos serão melhor embasadas. Portanto, o objetivo deste trabalho foi avaliar a eficiência dos métodos de extração com água 1:1,5 e extrato de saturação, bem como o extrator DTPA/CaCl 2 , em determinar os micronutrientes disponíveis para a rúcula crescida em substratos do tipo fibra de coco, casca de pinus e turfa.

\section{MATERIAL E MÉTODOS}

O experimento foi conduzido em casa de vegetação usando a rúcula como planta teste, a qual foi cultivada em substratos comerciais tipo fibra de coco, casca de pinus e turfa, com os valores de $\mathrm{pH}$ em água de 4,3; 5,9 e 5,5, respectivamente. $\mathrm{O}$ delineamento experimental foi inteiramente casualizado em esquema fatorial $3 \times 4$, com 5 repetições. Os tratamentos constituíram-se de três substratos (fibra de coco, casca de pinus e turfa) e quatro doses de adubação com micronutrientes (Tabela 1), com base na solução nutritiva (solução 1) de Furlani et al. (1999) para alface (mg L $\left.{ }^{-1}\right)$ : B $(0,61) \mathrm{H}_{3} \mathrm{BO}_{3} ; \mathrm{Cu}(0,13) \mathrm{CuSO}_{4} \cdot 5 \mathrm{H}_{2} \mathrm{O}$; Fe $(2,49)$ FeEDDHA-6\% Fe; Mn $(0,64)$ $\mathrm{MnSO}_{4} \cdot \mathrm{H}_{2} \mathrm{O}$ e $\mathrm{Zn}(0,25) \mathrm{ZnSO}_{4} \cdot 7 \mathrm{H}_{2} \mathrm{O}$. As concentrações de macronutrientes e molibdênio foram mantidas constantes em todas as soluções estudadas, sendo, em mg L ${ }^{-1}: \mathrm{N}_{-} \mathrm{NO}_{3}=174 ; \mathrm{N}^{-N_{4}}=24$; $\mathrm{P}=39 ; \mathrm{K}=183 ; \mathrm{Ca}=142 ; \mathrm{Mg}=38$; $\mathrm{S}-$ $\mathrm{SO}_{4}=52 ; \mathrm{Mo}=0,06$ (Furlani et al., 1999). No preparo da solução foram usados o nitrato de cálcio, nitrato de potássio, sulfato de magnésio, fosfato monoamônio e molibdato de sódio.

Na saturação dos substratos com essas soluções empregaram-se tubos de PVC de $30 \mathrm{~cm}$ de diâmetro por 55 cm de altura, tamanho suficiente para comportar um volume de aproximadamente $30 \mathrm{~L}$ de substrato. Na extremidade inferior do tubo de PVC colocou-se uma tampa, provida de um orifício central, onde foi conectada uma borracha para o escoamento da solução. Para cada tipo de substrato utilizaram-se 4 tubos de PVC. Em cada tubo adicionaram-se 25 $\mathrm{L}$ do substrato que foram incubados com as respectivas soluções de micronutrientes (Solução 1; 5; 10 e 20) . Foi necessário saturar os substratos diversas vezes até que a CE do lixiviado fosse a mesma da solução nutritiva aplicada (Tabela 1).

Após a saturação do substrato com a solução nutritiva com diferentes concentrações de micronutrientes fez-se a homogeneização dos substratos. Dos 25 $\mathrm{L}$ de substrato incubados separaram-se 10 L para as análises químicas de micronutrientes e $15 \mathrm{~L}$ para o cultivo de 8 sementes de rúcula (Eruca sativa), em vasos com capacidade de três L (16 cm altura x 20 cm diâmetro), constituindo a parcela.

Durante a condução do ensaio, os vasos foram mantidos com umidade de 
Tabela 2. Coeficientes de correlação (r) entre a concentração ou o acúmulo de micronutrientes (B, Cu, Fe, Mn e Zn) na parte aérea da rúcula e o teor desses micronutrientes extraídos dos substratos pelos diferentes métodos (Correlation coefficient (r) between the concentration or accumulation of micronutrients (B, Cu, Fe, Mn and $\mathrm{Zn}$ ) on the aerial part of arugula and the contain of these micronutriets extracted from the substracts through various methods). Campinas, IAC, 2005.

\begin{tabular}{|c|c|c|c|c|c|c|}
\hline & \multicolumn{2}{|c|}{ Fibra de coco } & \multicolumn{2}{|c|}{ Casca de pinus } & \multicolumn{2}{|c|}{ Turfa } \\
\hline & Concentrado & Acumulado & Concentrado & Acumulado & Concentrado & Acumulado \\
\hline & \multicolumn{6}{|c|}{ Boro } \\
\hline Ext. Sat. & 0,99 ** & $0,92 \mathrm{NS}$ & 0,98 * & 0,99 ** & 1,00 ** & $0,99 * *$ \\
\hline $1: 1,5$ & 0,99 ** & 0,93 NS & 0,98 * & 0,99 ** & 0,99 ** & 0,98 * \\
\hline \multirow[t]{2}{*}{ DTPA } & 0,99 ** & 0,93 NS & 1,00 ** & 1,00 ** & 1,00 ** & 0,98 * \\
\hline & \multicolumn{6}{|c|}{ Cobre } \\
\hline Ext. Sat. & 0,99 ** & 0,86 NS & 0,86 NS & 1,00 ** & $-0,34 \mathrm{NS}$ & $-0,62$ NS \\
\hline $1: 1,5$ & 0,92 NS & 0,67 NS & 0,48 NS & 0,83 NS & $-0,34 \mathrm{NS}$ & $-0,62$ NS \\
\hline \multirow[t]{2}{*}{ DTPA } & 0,87 NS & 0,59 NS & 0,66 NS & 0,92 NS & 0,11 Ns & $-0,28$ NS \\
\hline & \multicolumn{6}{|c|}{ Ferro } \\
\hline Ext. Sat. & $0,89 \mathrm{NS}$ & $-0,09 \mathrm{NS}$ & $0,89 \mathrm{NS}$ & 0,98 * & $0,47^{N S}$ & $-0,48$ NS \\
\hline $1: 1,5$ & 0,87 NS & $-0,14$ NS & 0,89 NS & 0,98 * & 0,50 NS & $-0,47^{N S}$ \\
\hline \multirow[t]{2}{*}{ DTPA } & 0,92 NS & $-0,04$ NS & $-0,07$ Ns & 0,25 NS & 0,93 NS & 0,14 NS \\
\hline & \multicolumn{6}{|c|}{ Manganês } \\
\hline Ext. Sat. & $0,68^{N S}$ & $0,21^{N S}$ & $0,12 \mathrm{NS}$ & $0,73^{N S}$ & $0,68 \mathrm{NS}$ & 0,67 NS \\
\hline $1: 1,5$ & 0,74 NS & $0,30 \mathrm{NS}$ & 0,12 NS & $0,75^{\text {NS }}$ & 0,48 NS & 0,46 NS \\
\hline \multirow[t]{2}{*}{ DTPA } & 0,79 NS & $0,37^{N S}$ & $-0,45$ NS & 0,62 NS & 1,00 ** & $0,99 * *$ \\
\hline & \multicolumn{6}{|c|}{ Zinco } \\
\hline Ext. Sat. & $-0,86 \mathrm{NS}$ & $-0,80 \mathrm{NS}$ & $-0,85$ NS & $-0,61$ NS & $-0,63$ NS & $-0,69 \mathrm{NS}$ \\
\hline $1: 1,5$ & $-0,95$ * & $-0,91$ NS & $-0,87$ NS & $-0,63$ NS & $-0,75 \mathrm{NS}$ & $-0,71 \mathrm{NS}$ \\
\hline DTPA & $-0,90$ NS & $-0,86$ NS & $-0,43$ Ns & $-0,68$ NS & $-0,78$ NS & $-0,84$ NS \\
\hline
\end{tabular}

$70 \%$, sendo pesados a cada 24 horas para reposição da água. Após 45 dias da semeadura, as plantas foram retiradas do vaso e separadas, em parte aérea e raízes. A parte aérea foi pesada (massa úmida), lavada e seca em estufa com circulação forçada de ar a $70^{\circ} \mathrm{C}$, pesada novamente para obtenção da massa seca, depois moída e submetida à digestão por via seca (Bataglia et al., 1983) para a extração dos micronutrientes e posterior determinação por espectrometria de emissão óptica por plasma de argônio (ICP-OES).

Na extração dos micronutrientes dos diferentes tratamentos empregaram-se os métodos: a) extrato de saturação (Warncke, 1986): rotineiramente usado nos Estados Unidos, considerado "método padrão” em estudos metodológicos. Em aproximadamente $400 \mathrm{~cm}^{3}$ de material (sem tratamento prévio) adicionou-se água deionizada até que a pasta apresentasse aspecto brilhante, ou quando o sulco feito por uma espátula desaparecesse rapidamente. Após uma hora em repouso, a pasta foi filtrada a vácuo em funil de Büchner contendo papel de filtro, aplicando-se sucção até obter

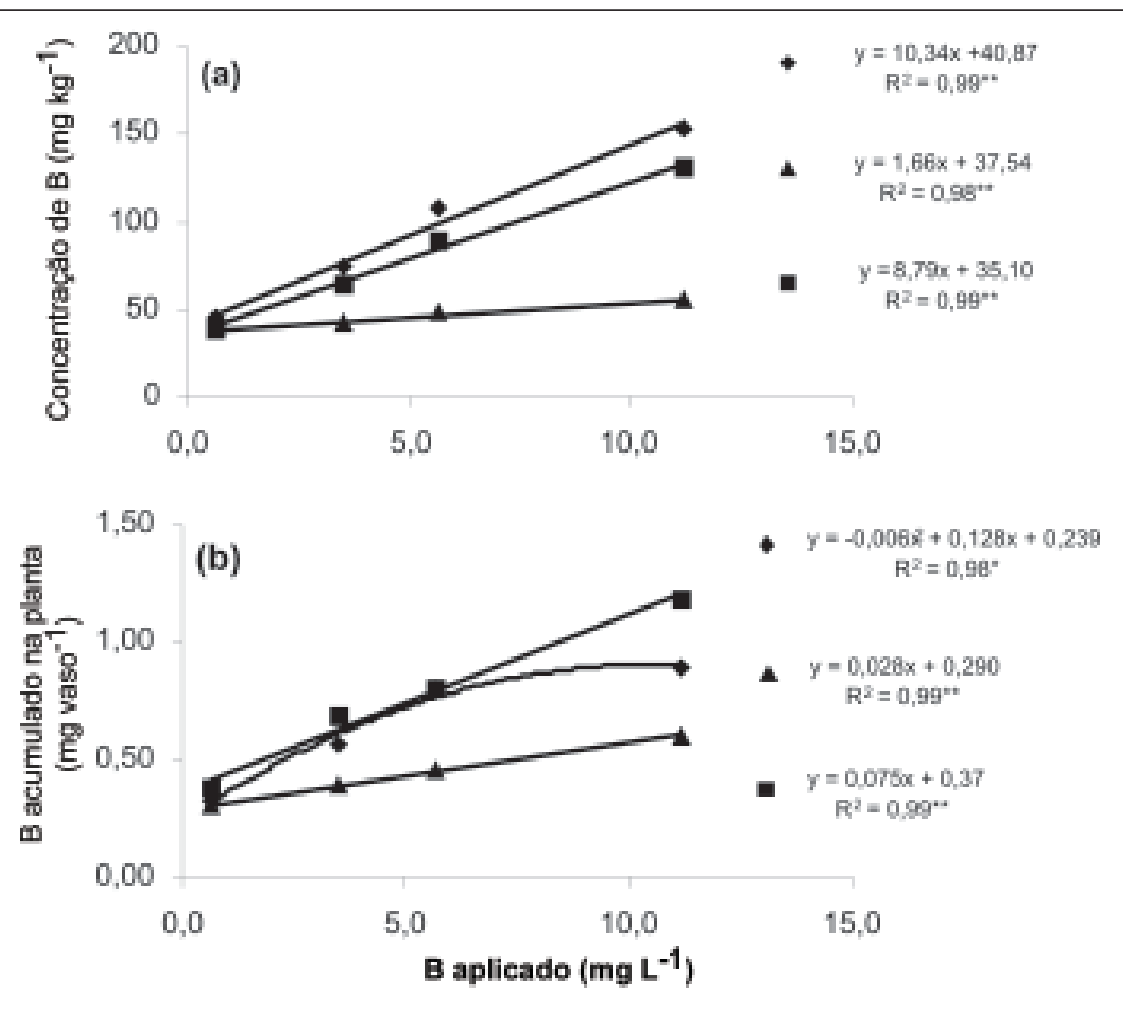

Figura 1. Relação entre a dose de boro aplicada na fibra de coco $(\mathbf{\bullet})$, casca de pinus $(\boldsymbol{\Lambda})$ e turfa $(\square)$ e a concentração de boro (a) ou o total de boro acumulado na parte aérea da rúcula (b) (Relation among the dosis of B applied to the coconut fiber $(\boldsymbol{\bullet})$, pinus bark $(\boldsymbol{A})$ and peat ( $\mathbf{a}$ ) and the concentration of B (a) or total accumulated B on the aerial part of arugula (b)). Campinas, IAC, 2005. 


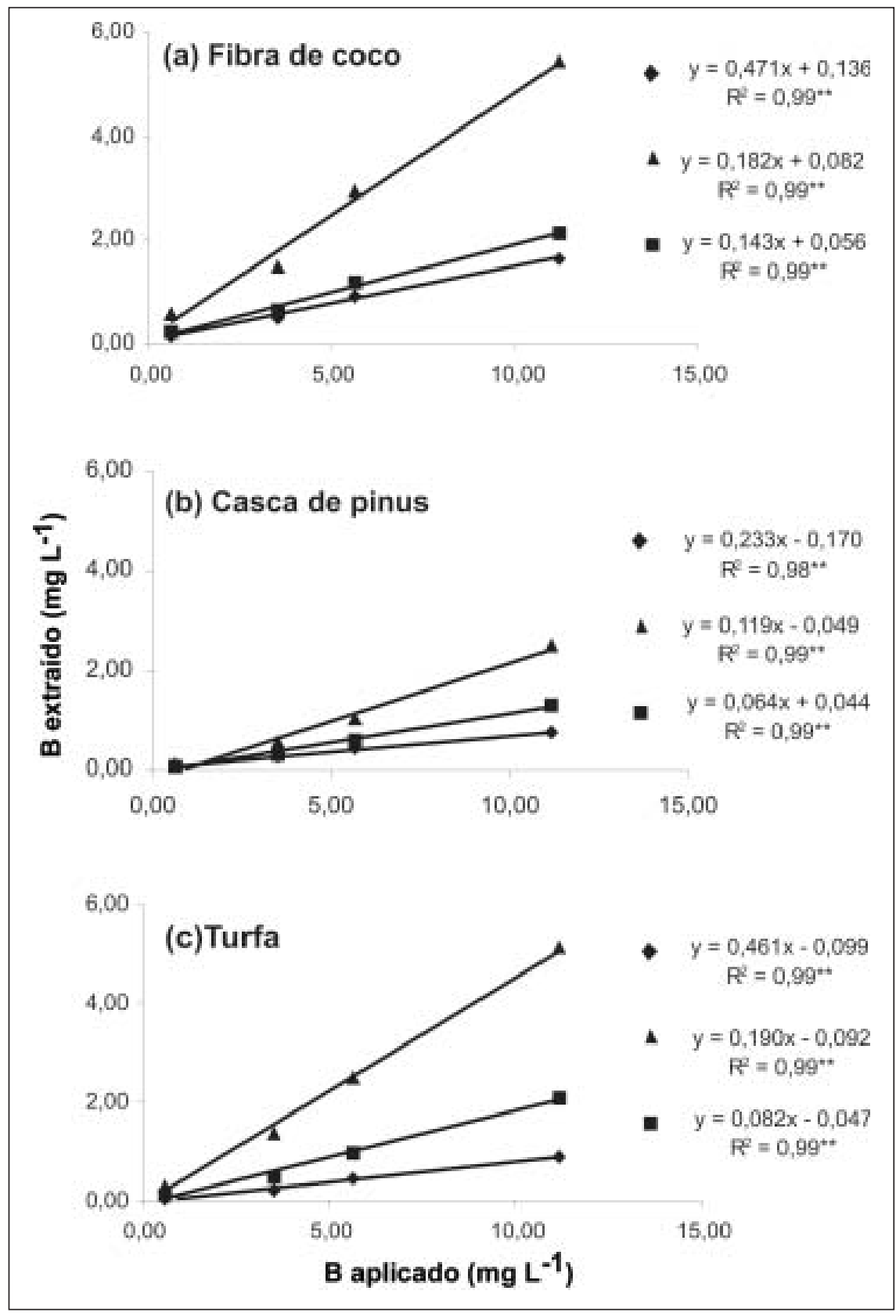

Figura 2. Relação entre o teor de boro aplicado nos substratos: (a) fibra de coco; (b) casca de pinus e (c) turfa e o teor desse extraído pelos métodos Extrato de saturação ( $\mathbf{A}), 1: 1,5$ ( e DTPA ( $\bullet$ ) (Relation among the dosis of B applied to the substrates: (a) coconut fiber; (b) pinus bark and (c) peat and their dosis after extraction through the methods Extrato de

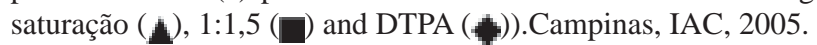

aproximadamente $25 \mathrm{ml}$ de extrato; b) método 1:1.5 v/v (Sonneveld et al., 1974; Sonneveld \& Elderen, 1994): rotineiramente utilizado pelos laboratórios da Holanda para determinação do pH, CE e macronutrientes em substratos. Para o tratamento prévio da amostra, empregou-se cerca de $200 \mathrm{~cm}^{3}$ de material que foram misturados com água deionizada até que, apertando-se levemente nas mãos a água escorresse por entre os dedos. Esse material foi colocado em um anel de $100 \mathrm{~cm}^{3}$ que recebeu uma pressão de $10 \mathrm{kPa}$. Para obtenção do extrato, em $100 \mathrm{~cm}^{3}$ desse material previamente tratado, misturaram-se $150 \mathrm{ml}$ de água deionizada. Logo a seguir, a suspensão foi agitada por $30 \mathrm{mi-}$ nutos usando agitador horizontal com 220 rpm e, posteriormente, filtrada em papel de filtro; c) DTPA/CaCl $\mathbf{2}$ (CAT) (DTPA 0,002 $\mathrm{mol} \mathrm{L}^{-1} / \mathrm{CaCl}_{2}$ 0,01 mol
$\mathrm{L}^{-1}, \mathrm{pH}$ 2,6) (Alt \& Peters, 1993): empregado por vários países da Comunidade Européia para determinação dos micronutrientes em substratos. Na extração usou-se a relação 1:5 (v/v) substrato/solução. Em $60 \mathrm{~cm}^{3}$ de substrato adicionaram-se $300 \mathrm{ml}$ da solução extratora de DTPA/ $\mathrm{CaCl}_{2}$. A suspensão foi agitada por uma hora em agitador horizontal a 220 rpm e, posteriormente, filtrada.

Todas as extrações foram feitas em triplicata e em cada extrato foram determinados os teores de micronutrientes por espectrometria de emissão óptica por plasma de argônio (ICP-OES).

Fêz-se a análise de variância do experimento e na comparação das médias empregou-se o teste Tukey, usando o nível de significância de 95\% de probabilidade. Para avaliar a eficiência dos métodos os resultados foram submetidos às análises de correlação e de regressão. Considerou-se como método eficiente em avaliar a disponibilidade de micronutrientes aquele que apresentou coeficiente de determinação significativo para a relação entre o teor de micronutriente no substrato e o seu teor na parte aérea da rúcula.

\section{RESULTADOS E DISCUSSÃO}

Para que um método seja eficiente em avaliar a disponibilidade de um nutriente ele deve apresentar correlações significativas e altas entre o teor do nutriente extraído pelo método em questão e a concentração desse na parte aérea da planta ou o seu acúmulo. De maneira geral, os métodos testados foram ineficientes em avaliar a disponibilidade de $\mathrm{Cu}, \mathrm{Fe}$, Mn e Zn para a rúcula (Tabela 2). Resultados positivos foram obtidos somente pelo uso do método extrato de saturação em quantificar o $\mathrm{Cu}$ disponível quando a rúcula foi crescida na casca de pinus e na fibra de coco, e para extrair o Fe da casca de pinus. No caso do Mn, o método eficiente foi o DTPA/ $\mathrm{CaCl}_{2}$ quando a turfa foi usada como substrato, e para o $\mathrm{Zn}$ a eficiência foi verificada para a extração com água na proporção 1:1,5 para a fibra de coco (Tabela 2).

Diante dos resultados obtidos para $\mathrm{Cu}, \mathrm{Fe}, \mathrm{Mn}$ e Zn será feita uma discus- 
são mais detalhada somente para o B, embora o objetivo do trabalho tenha sido avaliar a disponibilidade dos micronutrientes para a rúcula cultivada em três diferentes substratos.

A concentração de $\mathrm{B}$ ou o seu acúmulo na parte aérea da rúcula aumentou com o aumento das doses de B aplicadas e, também, variou conforme o substrato utilizado (Figura 1). A relação entre essas variáveis foi linear crescente, exceto para a fibra de coco no teor acumulado (Figura 1b) e apresentaram coeficiente de determinação acima de $0,98^{* *}$. As concentrações de B na parte aérea da rúcula nas doses 1 e 20 foram respectivamente, em $\mathrm{mg} \mathrm{kg}^{-1}$, de: 44,9 e 153,6 (fibra de coco); 39,4 e 132,02 (turfa) ; 38,1 a 55,5 (pinus). Os limites inferiores estão dentro da faixa de teor considerada adequada. Quando a rúcula foi crescida nos tratamentos que receberam as soluções 5; 10 e 20, tanto na fibra de coco como na turfa, as concentrações de B ultrapassaram o limite superior de $61 \mathrm{mg} \mathrm{kg}^{-1}$, sugerido como adequado por Furlani (1997), porém não apresentando sintomas visuais de toxicidade. De acordo com Mattos Jr. et al. (1995), sintomas de toxicidade de B em citros apareceram somente quando os teores foliares desse elemento foram superiores a $280 \mathrm{mg} \mathrm{kg}^{-1}$.

A diferença na concentração de $\mathrm{B}$ da parte aérea da rúcula, em função do tipo de substrato (Figura 1a), pode estar relacionada aos processos de adsorção desse elemento aos constituintes orgânicos. Conforme Alleoni (1996) existe uma relação positiva entre a matéria orgânica, pH e a adsorção de B no solo. Provavelmente, na casca de pinus o B esteja mais fortemente ligado aos complexos da matéria orgânica, o que o torna menos disponível em solução. $\mathrm{O}$ fato do $\mathrm{pH}$ da casca de pinus ser maior ( $\mathrm{pH} 5,9)$ em relação à turfa $(\mathrm{pH} 5,4)$ e à fibra de $\mathrm{coco}(\mathrm{pH}$ 4,3), ajuda a explicar a maior capacidade de adsorção de $\mathrm{B}$ pela casca de pinus e, conseqüentemente menor disponibilidade para as plantas. O efeito da calagem na diminuição da disponibilidade de $B$ para a couve flor foi observado por Melo \& Minami (1999). Tais resultados mostram a importância de se ter um método que seja eficiente em avaliar o teor disponível de B no substrato.
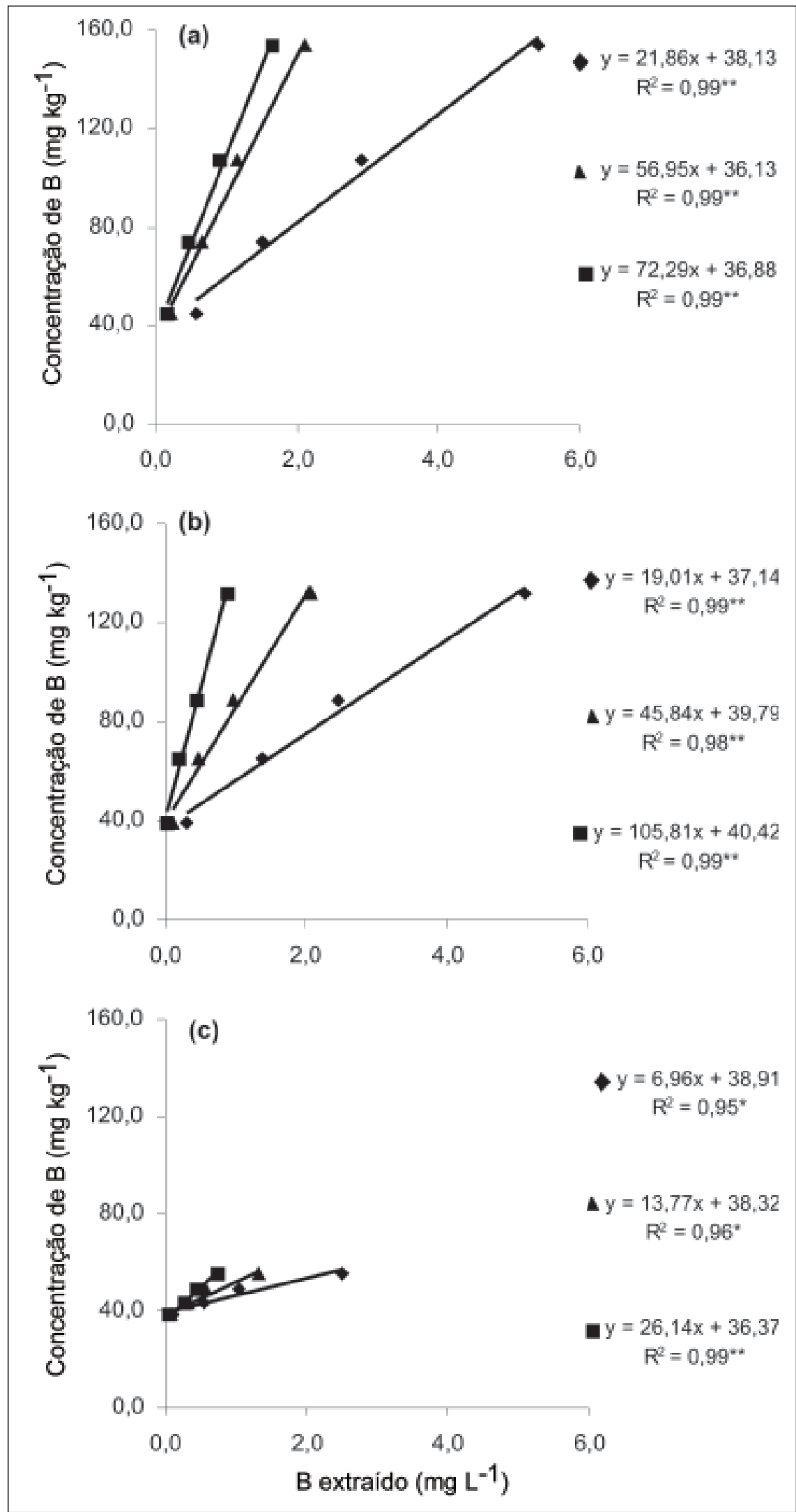

Figura 3. Relação entre o teor de boro extraído pelos métodos Extrato de saturação ( $\mathbf{A})$, 1:1,5 ( $\square$ ) e DTPA (४) nos substratos (a) fibra de coco; (b) casca de pinus e (c) turfa e a concentração de boro na parte aérea da rúcula (Relation among the $\mathrm{B}$ dosis extracted through the methods Extrato de saturação ( $\mathbf{\Delta}), 1: 1,5$ ( $)$ and DTPA (४) on the substrates (a) coconut fiber; (b) pinus bark and (c) peat, and the concentration of B on the aerial part of arugula). Campinas, IAC, 2005. 


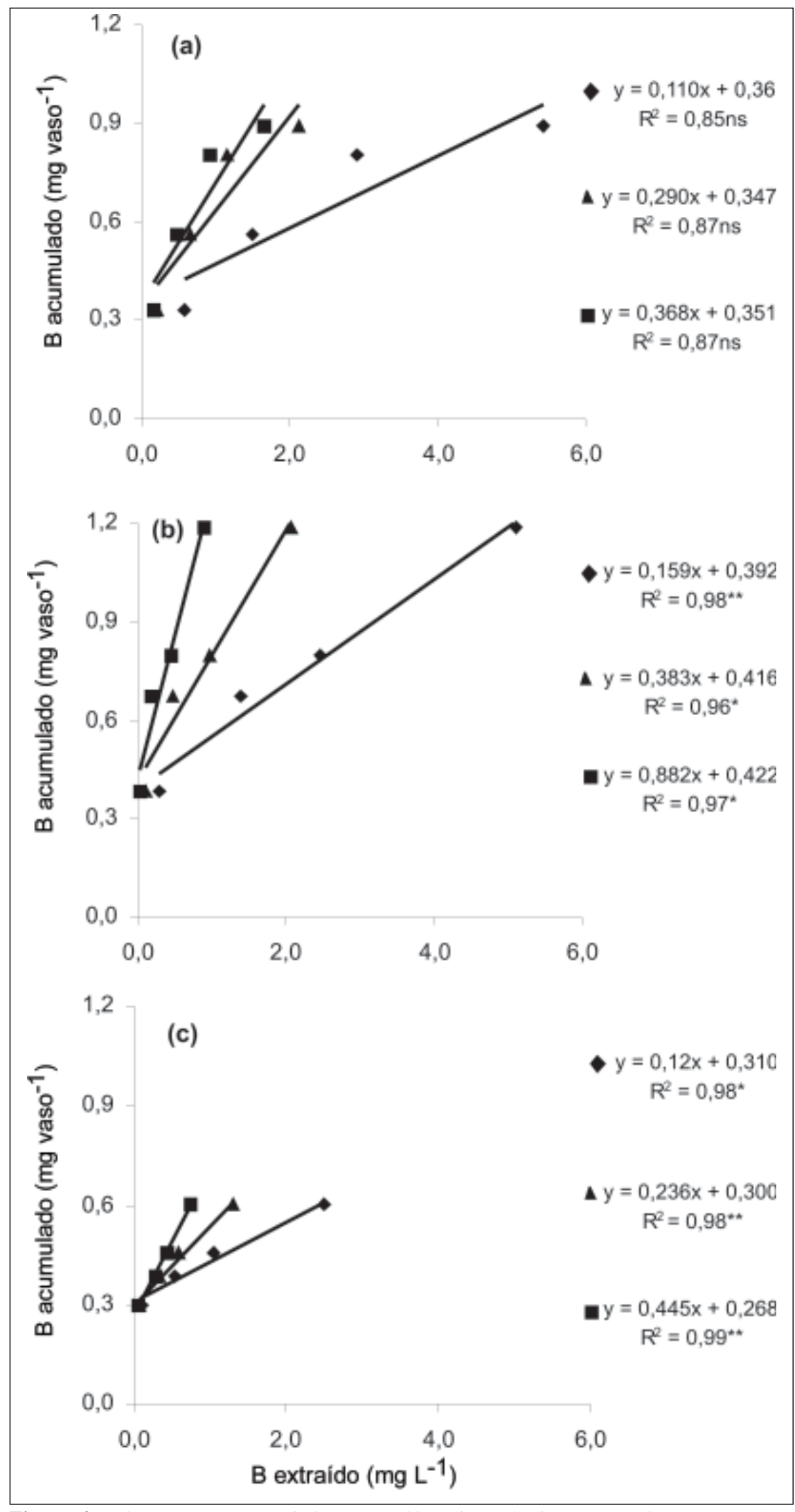

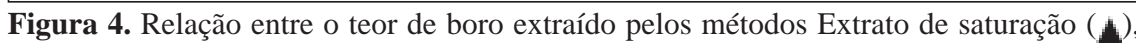
1:1,5 ( $\square$ ) DTPA ( $)$ nos substratos (a) fibra de coco; (b) casca de pinus e (c) turfa e o teor de boro acumulado na parte aérea da rúcula (Relation among the B dosis extracted through

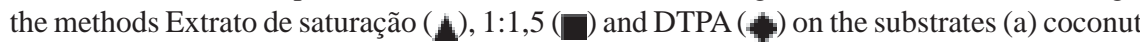
fiber; (b) pinus bark and (c) peat, and the dosis of B accumulated on the aerial part of arugula). Campinas, IAC, 2005.
Usando o extrato de saturação para extrair o B da casca de pinus os teores desse micronutriente variaram, em $\mathrm{mg}$ $\mathrm{L}^{-1}$, de 0,10 (solução 1 ) a 2,51 (solução 20). Na fibra de coco e na turfa os teores de $\mathrm{B}$, em $\mathrm{mg} \mathrm{L}^{-1}$, foram respectivamente, de: 2,92 e 2,47 (solução 10); 5,43 e 5,10 (solução 20) (Figura 2). Embora, não exista ainda uma interpretação da análise de B em substratos, Mattos Jr. et al. (1995) observaram que toxicidade de B em porta-enxertos de citros estava associada a teores maiores que $5 \mathrm{mg} \mathrm{kg}^{-1}$ no substrato (extraído com água quente). Menor crescimento do material vegetal com conseqüente atraso no período de formação da muda e perda da qualidade desejada foram relacionados à toxicidade de $\mathrm{B}$.

O comportamento dos extratores em função da dose de B aplicada foi muito semelhante, independentemente do substrato utilizado (Figura 2). Os ajustes observados foram do tipo linear crescente com valores de $\mathrm{R}^{2}$ de $0,99^{*}$, indicando que todos os métodos avaliados foram eficientes em discriminar o efeito da aplicação de boro.

A capacidade extrativa de B por cada método seguiu a seguinte ordem decrescente: extrato de saturação $>1: 1,5>$ DTPA, independentemente do tipo de substrato (Figura 2). Contudo, esse efeito foi mais pronunciado na fibra de coco seguido pela turfa (Figura 2). A seqüência de extração observada deve-se, provavelmente, ao fator diluição (relação substrato: água). O extrato de saturação é menos diluído, seguindo-se do método 1:1,5 e DTPA. Portanto, esperar-se ia maior concentração de $B$ no extrato de saturação e menor pelo uso do método DTPA. Conforme Sonneveld et al. (1974), quanto menor a diluição mais próximos ficam os resultados daqueles obtidos com o extrato de saturação.

Para que um método de análise seja eficiente em avaliar a disponibilidade de um determinado nutriente ele deverá apresentar correlações altas e significativas com o teor do nutriente na planta. A relação entre o teor de B no substrato e a concentração desse elemento na planta foi linear crescente e altamente significativa com $R^{2}>0,95$, para os três métodos de análise testados (Figura 3). 
Esses resultados devem-se, principalmente, ao fato do B estar na forma de ácido bórico $\left(\mathrm{H}_{3} \mathrm{BO}_{3}\right)$ que é muito solúvel em água e também ser a forma absorvida pelas plantas. Correlações positivas e significativas ( $\left.\mathrm{r}=38,3^{* *}\right)$ entre o teor de matéria orgânica e o B extraído pela água quente foram observados por Silva \& Ferreyra (1998). Portanto, pode-se afirmar que para o $\mathrm{B}$, todos os métodos podem ser utilizados na determinação do teor disponível às plantas.

Para o B acumulado na parte aérea da rúcula foi observada a mesma tendência daquela encontrada para a concentração de B na planta (Figura 4).

Além da eficiência do extrator em avaliar a disponibilidade do B, medida pela relação entre o B-planta e B-extrator, outros fatores são importantes quando se almeja selecionar métodos para uso em condições de rotina do laboratório. Esses aspectos são a amplitude do teor extraído, o tamanho da amostra empregada, a reprodutibilidade e repetibilidade do procedimento no laboratório, o tempo gasto na extração e o requerimento de equipamento especial.

O extrator que apresentou maior amplitude de extração de B foi o extrato de saturação e o menor o DTPA/ $\mathrm{CaCl}_{2}$. Essa amplitude é importante porque diminui o erro, principalmente de leitura. A quantidade de amostra usada em um determinado procedimento é relevante porque grande parte dos substratos é composta de vários materiais com características químicas e físicas diferenciadas (tamanho do material), o que interfere na homogeneidade de uma amostra pequena e conseqüentemente no teor extraído. Quanto ao tempo de extração, de maneira geral o método mais trabalhoso foi o extrato de saturação pela dificuldade de se definir com precisão o ponto de saturação para alguns materiais e o tempo para extração que é muito longo. Portanto, a escolha do melhor método é um conjunto de fatores que vai além da sua eficiência sob o ponto de vista agronômico - fator primordial. O procedimento deve se adequar às possibilidades de um laboratório de rotina, ter boa repetibilidade e reprodutibilidade.

Nenhum método foi eficiente para avaliar a disponibilidade de $\mathrm{Cu}, \mathrm{Fe}, \mathrm{Mn}$ e Zn para rúcula crescida nos substratos fibra de coco, casca de pinus e turfa.

Todos os métodos podem ser utilizados na determinação do teor disponível de $\mathrm{B}$ às plantas, sendo o extrato de saturação o método mais recomendado para as condições de rotina.

\section{REFERÊNCIAS}

ABREU MF; ABREU CA; BATAGLIA OC. 2002. Uso da análise química na avaliação da qualidade de substratos e componentes. In: ENCONTRO NACIONAL SOBRE SUBSTRATO PARA PLANTAS, Anais..., Campinas: Instituto Agronômico, p. 17-28, (Documentos IAC, 70).

ABREU CA; FURLANI AC; ABREU MF; BATAGLIA OC; FURLANI PR. 2004. Micronutrient determination in different water extracts of coir fiber substrate incubated with mineral fertilizers. In: INTERNATIONAL SYMPOSIUM ON SOILLESS CULTURE AND HYDROPONICS, Anais..., 9., Almeria: Universidad de Almeria, p. 113.

ALLEONI LRF. 1996. Adsorção de boro em podzólico e latossolos paulistas. Piracicaba: USP-ESALQ. 72p (Dissertação de mestrado)

ALT D; PETERS I. 1993. Analysis of macro and trace elements in horticultural substrates by means of the $\mathrm{CaCl}_{2} / \mathrm{DTPA}$ (CAT) method. Acta Horticulturae 342: 287-292.

BOAVENTURA PSR. 2003. Demanda por nutrientes de mudas cítricas produzidas em substrato em ambiente protegido. Campinas: Instituto Agronômico, 62p (Dissertação de mestrado)

BATAGLIA OC; FURLANI AMC; TIXEIRA JPF; FURLANI PR; GALLO JR. 1983. Métodos de análise química de plantas. Campinas, Instituto Agronômico, 48p. (Boletim técnico,78).

BATAGLIA OC; FURLANI PR. 2004. Nutrição Mineral e Adubação para cultivos em substratos com atividade química. In: ENCONTRO NACIONAL SOBRE SUBSTRATO PARA PLANTAS, 4., Viçosa. Anais... Viçosa: UFV, p.106-128.

BUCHER AS; SCHENK MK. 2000. Characterization of phytoavailable $\mathrm{Cu}$ in compost-peat substrates and determination of toxcity level. Journal of the American Society for Horticultural Science 125: 765-770.
COMITÉ EUROPEÉN DE NORMALISATION (CEN). 2003a. EN 13651- Soil improvers and growing media- Extraction calcium chloride/ DTPA (CAT) soluble elements. Brussels.

COMITÉ EUROPEÉN DE NORMALISATION (CEN). 2003b. EN 13652- Soil improvers and growing media- Extraction of water soluble elements. Brussels,

FURLANI PR. 1997. Instruções para o cultivo de hortaliças pela técnica de hidroponia-NFT. Campinas, Instituto Agronômico, 30p. (Boletim técnico,168).

FURLANI PR; SILVEIRA LCP; BOLONHEZI D; FAQUIN V. 1999. Cultivo hidropônico de plantas. Campinas: Instituto Agronômico, 52p. ( Boletim Técnico, 180).

FURLANI AMC; ABREU MF; ABREU CA; FURLANI PR; BATAGLIA OC. 2004. Determination of available macronutrients, $\mathrm{pH}$ and EC in coir fiber substrate incubated with mineral fertilizers. In: INTERNATIONAL SYMPOSIUM ON SOILLESS CULTURE AND HYDROPONICS, 9., Almeria: Anais...Almeria: Universida de Almeria, p. 42-43.

MATTOS JÚNIOR D; QUAGGIO JA; CARVALHO AS; ABREU MF. 1994. Substratos para a produção de mudas cítricas em recipientes: caracterização da toxicidade de boro. Laranja 16: 255-262.

MELO S; MINAMI K. 1999. Efeitos do molibdênio e da calagem no crescimento da couve - flor cv. Shiromaru II. Scientia Agricola 56: 235-237.

SILVA FR; FERREYRA H. 1998. Boro total e solúvel e suas relações com alguns atributos dos solos do Estado do Ceará. Revista Brasileira de Ciência do Solo 22: 595-602.

SILVEIRA RLVA; MOREIRAA; TAKASHI EN; SGARBI F; BRANCO EF. 2002. Sintomas de deficiência de macronutrientes e de boro em Eucalyptus grandis com Eucalipytus urophylla. http:www.dcf.ufla.Br/cerne/Revista. 8(2).

SONNEVELD C; ENDE J; DIJK PA. 1974. Analysis of growing media by means of a 1:1,5 volume extract. Communications in Soil Science and Plant Analysis 53: 183-202.

SONNEVELD C. 1988. Analytical methods for substrates in the Netherlands. Acta Horticulturae 221: 413-416.

SONNEVELD C; ELDEREN CW. 1994. Chemical analysis of peaty growing media by means of water extraction. Communications in Soil Science and Plant Analysis 25: 31993208.

WARNCKE DD. 1986. Analyzing Greenhouse growth media by the saturation extraction method. Hortscience 21: 223-225. 